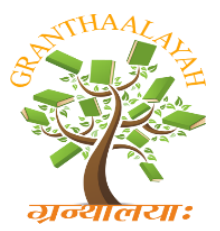

\author{
INTERNATIONAL JOURNAL OF RESEARCH - \\ GRANTHAALAYAH \\ A knowledge Repository
}

\title{
ECO-FRIENDLY TECHNOLOGIES AND ITS EFFECTS
}

\author{
Pratibha shrivastava \\ Dept. of Psychology Govt. Girls P.G. College, Ujjain (M.P.)
}

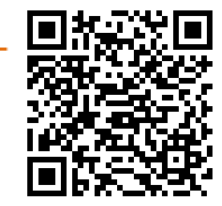

\section{ABSTRACT}

Eco-friendly technologies involved making use of alternative energy source which is abundant to generate renewable energy, reducing the amount of resource which is limited used through the conventional like fossil fuel. For example renewable resources like sunlight, sea water and co2 which are abundant generating alternative resource like biofuel, solar energy, freshwater and air purification through greenhouse, vegetation and halophytes cultivation stabilize the degraded desert soil and as wind breaks reduce the impact of pollutants on the environment.

Keywords:

Eco-friendly technologies, alternative energy source, greenhouse, environment.

\section{INTRODUCTION}

In some areas of green technologies such as water recycling and purification through natural less destructive renewable methods used for seawater in the dessert environment is not burden with the waste while creating opportunity to produce various products a fresh. These are also cheaper as well as using these waste materials recycle it in order to produce the new goods and products. This makes eco technologies cheaper for the producer and manufacturer in the long run. This is because though we may not see the savings right away when we start using sustainable technologies, we will realize that the money we save long term will be quite substantial.

Using biodegradable materials can be advantage for the reducing waste and impact to the environment and the human body. These materials having multiples characteristic making electronics circuits, tiny, flexible, stretchable and capable of dissolvable completely or partially enable us keeps our earth sustainable through reducing the amount of electronic waste polluting the landfill. Scientist like Professor John Roger and his working universities has announced making electronic component having disappearing act, and capable being completely vanish or partially disappear benefit health and the environment possible opportunities improving lifestyle and our environment.

\section{THE BENEFITS OF AN ENVIRONMENTALLY FRIENDLY BUSINESS}

Running an environmentally friendly business helps you reduce your impact on the environment and preserves natural resources. Our business can help the environment in many ways. For example, we can:

- Use products that reduce your reliance on natural resources (e.g. rainwater tanks, solar hot water systems)

- Use products that are made from recycled material (e.g. office supplies made from recycled plastic, furniture made from recycled rubber) 
- Look at all your business activities to see if you can do anything differently (e.g. reducing air travel by holding conference calls instead of interstate meetings).

- Making your business environmentally friendly not only benefits the environment but can also save you money.

\section{RECYCLING REDUCES COSTS}

Avoiding, reducing, reusing and recycling can lower your costs. For example, a few simple changes to how you deal with paper can involve your staff in environmentally friendly processes while saving you money:

- Avoid using materials unnecessarily

- Reduce your paper needs by asking staff to print double-sided

- Reuse by encouraging staff to use scrap paper for message-taking instead of purchasing message pads

- Recycle by shredding excess paper - you could recycle this commercially or invite staff to take it home for their compost or mulch heaps.

\section{GOOD PRACTICE CAN ATTRACT NEW CUSTOMERS}

Promoting your environmentally friendly methods can set your business apart from your competitors and attract new customers who want to buy products and services from an environmentally friendly business. Before making any environmental claims about your products, you should read the Australian Competition and Consumer Commission's green marketing and the Australian Consumer Law to help you comply with the Competition and Consumer Act 2010 (which replaced the Trade Practices Act 1974 on 1 January 2011). Focusing more on your environmental impacts can also help to attract and retain staff.

\section{IMPROVES SUSTAINABILITY}

Reducing the environmental impact of your business will improve the sustainability of your business. If you are less dependent on natural resources than your competitors and have ways to deal with rising costs due to climate change, your business will have a greater chance of long-term success.

\section{FEW EXAMPLES OF ECO-FRIENDLY TECHNIQUES}

\section{Water Jug Meets Mainframe}

Greening computers isn't so easy, and that's why it's amazing that the Lenovo ThinkPad L420 and L520 both incorporated up to $30 \%$ recycled material from office water jugs and used IT equipment in their LCD cover, palm rest, and case. Both are $40 \%$ more energy-efficient than their predecessors and promise lower carbon dioxide emissions, and even the packaging has been reduced 20\% (and is now 100\% recyclable, meaning no giant Styrofoam blocks in that box).

\section{Solar Speakers}

Even if these speakers weren't solar, they'd be cool. The Etón Rukus wireless speakers, available this summer, will come with an AC adapter and solar panels, making the product one of the few portable speakers that can run as long as the sun is shining. It connects via Bluetooth, sports an eink display that is more energy-efficient than others regardless of the source you use, and has a powerful sound being lauded by tech pundits. 


\section{Alarmingly Efficient}

There is probably no cooler home swag than the Bedol Water Alarm Clock. It uses no batteries or electricity, and you only have to replace the water every six months in order to keep it running smoothly. The new Squirt model even looks like a cute, colorful water drop.

\section{Eco Computers}

More eco award-winners in the computing category include the HP Pavilion, which boasts a mercury-free screen, and the Sony Vaio W Series notebook, with a plastic chassis made partly of recycled CDs and a carrying case made from old soda bottles. Better yet, Apple's iPad 2 is ecoand energy-efficient with a 10-hour battery, casing made from recyclable aluminium and glass, and a display that's made without arsenic, mercury, bromine, and polyvinyl chloride - all toxic chemicals found in other computing products.

Sustainable agriculture ensures that agricultural goods and products produced have fewer chemicals and are more organic whilst maintaining healthier soil quality and nutrients through various methods like recycling, rotating crops, composting replenishing nutrients and prevent pest through biological control reduce use of synthetic pesticides and fertilizer.

The greatest benefits of knowing what eco-friendly technology are the environment is choosing to use product that made from material preserved the environment and therefore does not degenerate at a fast rate. This is because when there is less waste produces, during the manufacture or production of products and the energy used is renewable which is less stressful on the environment there is less pollution and polluting chemicals and other substances. 